\title{
Simulated Acid Rain-induced Alterations in Flowering, Leaf Abscission and Pollen Germination in Sunflower (Helianthus annuus L.)
}

\section{*11NAND LAL, HEMLATA SINGH; PRITI SACHAN}

\author{
Department of Life Sciences, C.S.J.M. University, Kanpur-208024, INDIA \\ *Corresponding Author: Nand Lal \\ E-mail address: $\underline{\text { nl_pr@yahoo.co.in }}$
}

\begin{abstract}
This study examined the effects of simulated acid rain (SAR) of different $\mathrm{pH}$ [distilled water-7.0 (control), 5.7, 4.5 and 3.0] on leaf abscission, flowering and pollen germination in sunflower (Helianthus annuus L.) cv. 'Morden' as test system under field conditions in sandy loam soil with sufficient organic matter, pale yellow in color and $\mathrm{pH} 7.3$ and $65 \%$ water holding capacity. Acid rain solution $(30 \mathrm{ml} / \mathrm{plant})$ was sprayed on plants at weekly intervals starting from two leaved stage till initiation of flowering in the early morning under natural environment. Evaluation of SAR effects on budding, flowering, leaf abscission and pollen development revealed that initiation and duration of budding and flowering altered significantly in test plant with decreasing $\mathrm{pH}$ of acid rain solution. Acid rain application showed early leaf abscission and reduction in pollen germination percentage and pollen tube length. Effects of SAR increased more dramatically with the increase of SAR acidity. The study indicates the sunflower plant turns to be an acid rain sensitive system and demands for breeding with acid rain tolerant varieties in view of expanding acid rain geographical areas and growing industrialization. (C) JASEM
\end{abstract}

https://dx.doi.org/10.4314/jasem.v21i2.9

Keywords: Simulated acid rain, Helianthus annuus, flowering, leaf abscission, pollen germination, sunflower.

Acid rain/deposition (including snow and fog), formed due to reaction of oxides of sulphur and nitrogen with atmospheric moisture, has become a global environmental concern in last few decades. Natural atmospheric precipitation is slightly acidic due to dissolution of $\mathrm{CO}_{2}$ whereas acidic precipitations contain concentration of $\mathrm{H}^{+}$greater than $2.5 \mu \mathrm{eq}^{-1}$ and $\mathrm{pH}$ less than 5.6 and exert harmful effects on living and nonliving components of terrestrial and aquatic ecosystems. Agricultural crops show wide range of sensitivity to rain water acidity and pollen germination and tube growth are among the sensitive botanical indicators of atmospheric pollution. Several studies conducted in field and greenhouse have demonstrated that acid rain exposure of plants results in poor growth, premature leaf abscission, delayed flowering, decreased flower size, reduced pollen fertility, low seed set and yield (Pal and Kumar, 2000; Dursun et al., 2002; Lal and Singh, 2012; Lal, 2016).

The acidic precipitation damages various kinds of vegetation including Triticum aestivum (Kausar et al., 2010), Capsicum annuum (Pal and Kumar, 2000), Solanum lycopersicum (Dursun et al., 2002) and Coriandrum sativum (Kazim, 2007). Herbaceous plants are more sensitive to direct injury by acid rain than woody plants. The effect of acid deposition on higher plants arises in two ways- either through foliage or through roots and affects nutrient storage function of the soil by increasing breakdown of electrostatic bonds responsible for nutrient absorption by soil particles (Naqvi et al., 2010). Verma et al. (2010) observed decreased growth and fruiting in three crops (Capsicum annuum, Lycopersicum esculentum and Solanum melongena) upon exposure to simulated acid rain (SAR). In a recent study on Capsicum annuиm L., SAR with increased acidity levels has been shown to cause negative effects on the growth and exposure to SAR at $\mathrm{pH} 4$ and below drastically suppressed growth characteristics (Bamidele and Eguagie, 2015). The present study aimed to assess the impact of simulated acid rain of different $\mathrm{pH}$ on budding, flowering, leaf abscission and pollen germination in sunflower (Helianthus annuus L., Family-Asteraceae), an important annual herbaceous oilseed and ornamental crop.

\section{MATERIALS AND METHODS}

The present study was carried out with sunflower variety 'Morden' in the experimental plot available at Oilseed Farm, C.S.A.U.A.T., Kanpur having sandy loam soil with sufficient organic matter, pale yellow in color and pH 7.3 and $65 \%$ water holding capacity. Sowing of sunflower variety 'Morden' was done in second week of April at an inter-row spacing of 60 $\mathrm{cm}$. The seeds were sown at a depth of about $5 \mathrm{~cm}$ in 
the soil. After 15 days of sowing, thinning operation was done and $60 \mathrm{~cm}$ inter-row and $30 \mathrm{~cm}$ inter-plant spacing (within the row) was maintained finally. During the period of crop growth the maximum and minimum temperature ranged 38.13 to $24.03^{\circ} \mathrm{C}$, atmospheric moisture ranged 64.23 to $34.36 \%$ and saturated vapor pressure ranged 20.2 to 18.96 . The Average rainfall, Evaporation and Sunshine were $1.11 \mathrm{~mm}, 8.15 \mathrm{~mm} / \mathrm{d}$ and 7.43 hour, respectively. After pre-sowing irrigation in the first week of April, two additional irrigations were provided in mid-May and first week of June, respectively. Field experiment was laid out in a randomized block design and comprised of four treatments including control with three replications. There were five rows of ten plants in each treatment to create different SAR treatments. Three concentrations of SAR i.e. $\mathrm{pH} 3.0,4.5,5.7$ and control $(\mathrm{pH} 7.0)$ were applied in respective plots. These plots were irrigated with normal deionized water.

Simulated acid rain (SAR) of different concentrations was prepared by mixing conc. of $1 \mathrm{~N}$ nitric acid $\left(\mathrm{HNO}_{3}\right)$ and $1 \mathrm{~N}$ sulphuric acid $\left(\mathrm{H}_{2} \mathrm{SO}_{4}\right)$ in 1: 2 molar ratios. The mixture was diluted with deionized water for preparation of solutions of $\mathrm{pH} \mathrm{5.7,} \mathrm{4.5,} \mathrm{and} \mathrm{3.0,}$ respectively. The plants sprayed with distilled water ( $\mathrm{pH}$ 7.0) were used as control. Acid rain sprayings were given in the early morning to avoid its application under high temperatures and high irradiance during the day. All treatments of SAR and control plants were treated with $30 \mathrm{ml}$ solution/plant of different $\mathrm{pH}$ (SAR treatments), starting from two leaves stage till initiation of first flower buds at weekly intervals.

The days taken to first flower bud initiation were recorded at peak growth stage in terms of days taken to first bud initiation and duration (period) of bud initiation in days. Days to first flower bud initiation were calculated since sowing of seed to appearance of first sunflower size flower bud and duration of bud initiation were recorded from first to last bud initiation since sowing of seed to appearance of first to last flower bud.

The data on flowering were recorded in terms of days taken to fist flower opening, duration (period) of flowering and average flower size $(\mathrm{cm})$. Days taken for the appearance of the first full size flower in each plot was recorded by visual observation since the date of sowing of seed and days taken for flowering were calculated for nine plants selected randomly. The number of days taken from date of first flowering to last flowering constituted duration of flowering and were recorded by taking average of nine plants in each treated plots and control. Flower size was recorded using measuring scale on nine flowers selected randomly in each treatment when the flowers were fully opened and size was expressed as diameter $(\mathrm{cm})$ of flowers.

Observations on the leaves were taken visually and also with the help of the lens. Leaf abscission level was recorded in order to monitor total number of leaves/plant and fallen number of leaves/plant. For total number of leaves/plant, all fully opened leaves were counted at peak growth stage starting from the base to the apex of the plant in the sampled plants (including fallen leaves). Total fallen numbers of leaves/plants were calculated at peak growth stage and the data in percentage were calculated using the formula given below:

\section{Fallen number of leaves $\times 100$ \\ Total number of leaves}

The pollen grains from freshly dehisced anthers of treated plants were collected separately. Pollen grain germination was tested on media composed of $20 \%$ sucrose and $20 \mathrm{ppm}$ potassium tetra borate $\left(\mathrm{K}_{2} \mathrm{~B}_{4} \mathrm{O}_{7}\right)$ which was converted into semi-solid medium by adding the $1 \%$ agar as a solidifying agent. Pollen grains were placed on a slide with thin layer of medium and then stained with acetocarmine dye. Slides were kept in a $60 \%$ humid chamber and incubated at $25 \pm 3{ }^{\circ} \mathrm{C}$. The germinated pollen grains were counted under a compound microscope (binocular) 20 minutes after shedding of pollen grains on the medium. The total number of pollen grains and number of germinated pollen grains were counted in microscopic fields. Pollen viability was computed as the ratio of germinated pollen grains to total pollen grains. Any pollen grains with a tube length more than a half of the grain diameter were regarded as germinated. For each treatment, 200-300 pollen grains were counted for germination and lengths of 60 pollen grains were measured in $\mu \mathrm{m}$ using an Ocular Micrometer.

\section{RESULTS AND DISCUSSION}

The floral bud formation was found directly affected with SAR concentration. In case of control, the days taken to first flower bud initiation was recorded 52.11 days from sowing of seeds. Bud initiation took minimum days in control and number of days increased at decreasing $\mathrm{pH}$ level from 5.7, 4.5 and 3.0 to $53.11,54.11$ and 57.88 days respectively (Figure 1). The maximum difference of first bud initiation was recorded between $\mathrm{pH} 4.5$ and 3.0. There are no reports for the effect of SAR on budding behavior of 
sunflower. However, Chehregani and Kavianpour (2007) reported that the buds of bean plants showed some developmental abnormalities including smaller embryo sac due to acid rain.

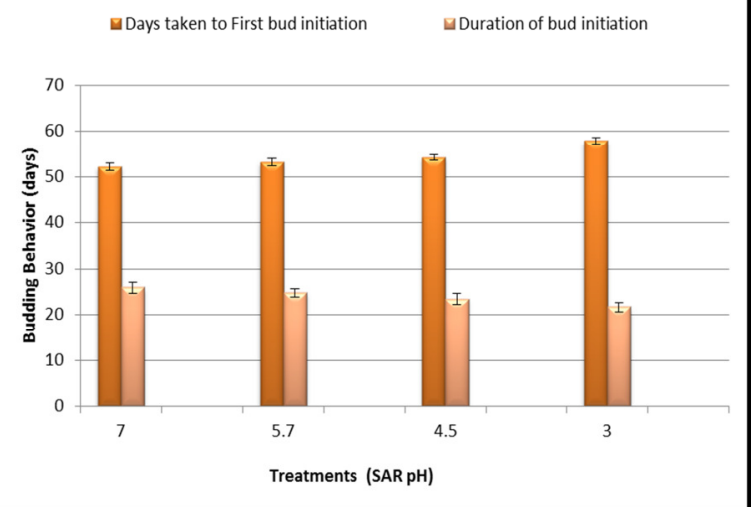

Fig.1. Effect of SAR on budding behavior in sunflower (H. annuus)

The plants showed erect type of initiation of budding in control while they turned erect to partial erect at pH 5.7 and $\mathrm{pH} 4.5$ and fully drooping type at $\mathrm{pH}$ 3.0. In case of control plants, the duration (period) of bud initiation (days) was observed 25.88 days. Bud initiation period was decreased with increasing level of acidity i.e. 24.77, 23.44 and 21.66 days at $\mathrm{pH} 5.7,4.5$ and 3.0, respectively (Figure 2). The pH 4.5 and 3.0 showed significant difference as compared to control. The application of SAR resulted in preponement of floral bud initiation in sunflower. In case of control plants, first flower was opened in 55.88 days. SAR application of $\mathrm{pH} 5.7$ took 56.77 days to have the first flower opening. As the acidity of SAR increased, days taken to first flower opening also increased and it recorded 57.88 in $\mathrm{pH} 4.5$ followed by 3.0 with 62.11 days (maximum).

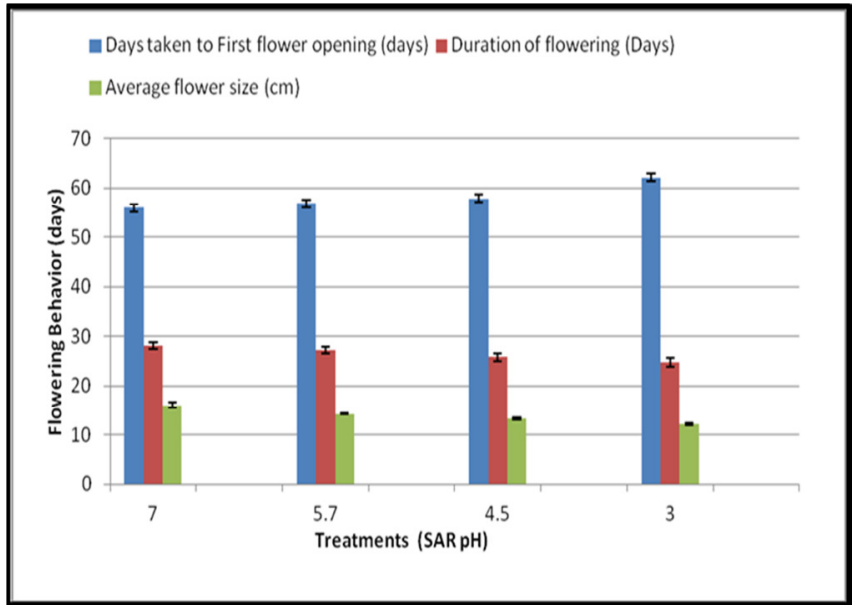

Fig. 2: Effect of SAR on flowering behavior in Sunflower (H. annuus)

Duration of flowering was recorded maximum (28.22 days) in case of control and further increase in acidity showed decreasing trend on duration of flowering. In SAR showered plants, period of flowering was 27.22, 25.88 and 24.77 days at $\mathrm{pH} 5.7,4.5$ and 3.0, respectively. The difference in duration of flowering among treatments was maximum between $\mathrm{pH} 5.7$ (27.22) to 4.5 (25.88). Pal and Kumar (2000) investigated effect of SAR in Capsicum annuum and found that numbers of flowers were decreased in treated plants for all treatments at all $\mathrm{pH}$ values. Milton and Abigael (2015) in their phenological observations on okra (Abelmoschus esculentus L.) also reported delayed first flower emergence with increasing SAR concentration. The effect of SAR became more pronounced with increasing acidity and duration of treatments.

SAR influenced the flower head diameter significantly. Average head diameter of plant size 
was recorded $16.04 \mathrm{~cm}$ in the case of control plants and decrease over the control in head diameter was recorded by $3.87 \mathrm{~cm}$ or $33.87 \%$ in $\mathrm{pH} 3.0,2.74 \mathrm{~cm}$ or $17.08 \%$ in $\mathrm{pH} 4.5$ and $1.79 \mathrm{~cm}$ or $11.15 \%$ in $\mathrm{pH} 5.7$ (Figure 3). Present observations in sunflower on average flower size are confirmed with the study of Khalid and Qureshi (2004). Delay in opening of the first flower, duration of flowering and reduce flower size seem to be due to toxic effects of acids on sunflower tissues.

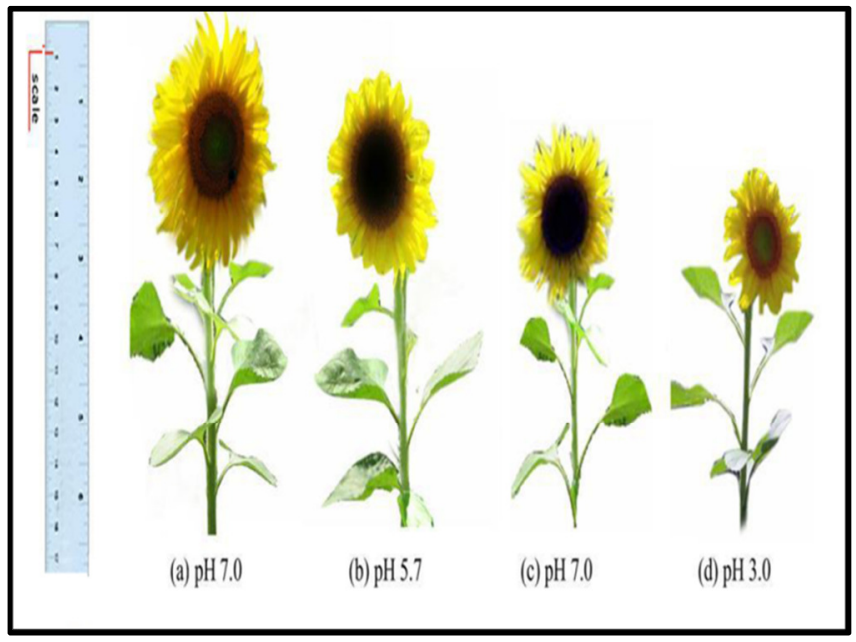

Fig. 3: Comparative effect of SAR on head diameter of Sunflower (H. annuus).

Leaf is the most sensitive plant organ to acid rain. Acid rain treatment at $\mathrm{pH} 3.0$ induced the formation of pale brown necrotic spots on the leaves. Necrotic symptoms first appeared along the vein and spread gradually into the interveinal areas. When young leaves were exposed to acid rain at $\mathrm{pH} 3.0$ during the early development stage, they became severely necrotic, crinkled and wrinkled. However, mature leaves were only slightly injured (Figure 4).

The plant leaf abscission was recorded $6.49 \%$ in the case of control. At pH 5.7 leaves showed $10.59 \%$ abscission and at $\mathrm{pH} 4.5$ leaf abscission was further increased with $12.31 \%$. Maximum leaves abscission were observed at $\mathrm{pH} 3.0(15.10 \%)$ as compared to control (Figure 5). Verma et al. (2010) studied the impact of simulated acid rain on three crops species viz. Capsicum annuum, Lycopersicon esculentum and Solanum melongena and observed that the leaf number in comparision to control was reduced $60 \%$ in L. esculentum, $50 \%$ in C. annuum, and $70 \%$ in $S$. melongena. In another study on Solanum lycopersicum L., Eguagie (2015) reported that SAR induced reduction in number of leaves with declining $\mathrm{pH}$ value of acid rain. The percentage of fallen leaves was also significantly higher at $\mathrm{pH} 3.0$ than at all other treatments. These studies proved that the old leaves of all these plants are readily exposed and abscission of leaves started on first week of exposure. Sulfur dioxide $\left(\mathrm{SO}_{2}\right)$ damages cell on the surface of leaves, depending on the concentration and the amount of water present and causes stomata either to close or to open, in either case disrupting the flow of water through plants (Sharma and Kaur, 1994). 

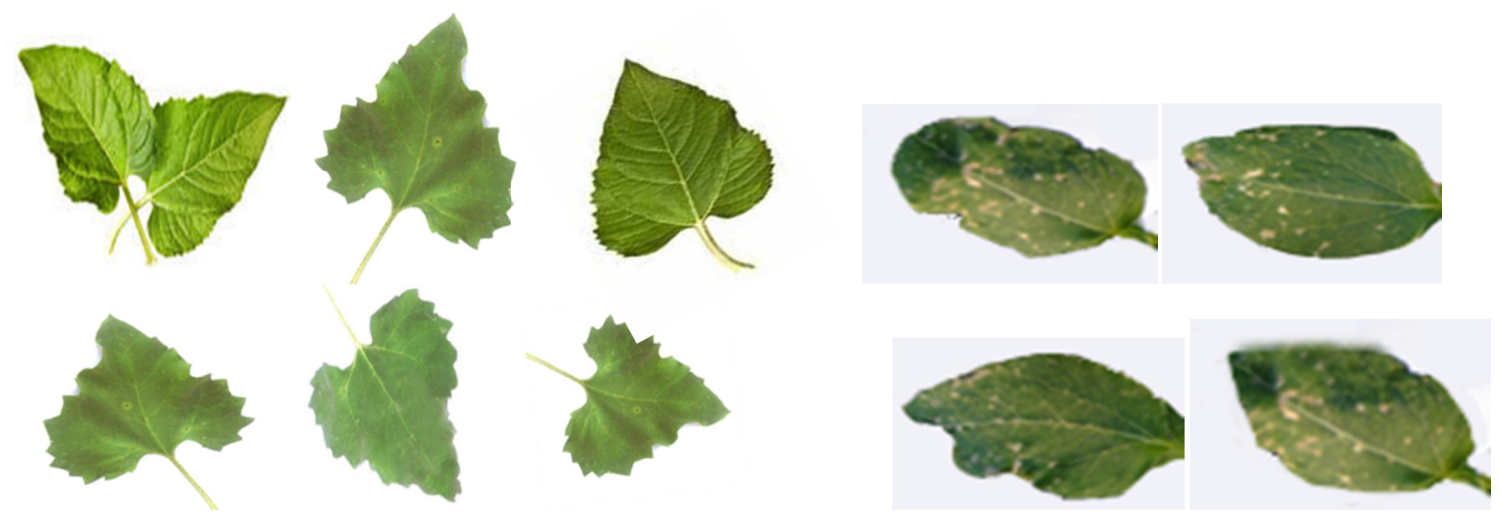

(a) Mature leaves

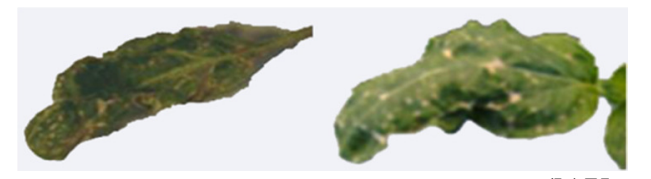

(b)Young leaves treated

Fig. 4: Comparative effect of SAR on leaves in sunflower (H. annuus)

(a) Mature leaves, (b) young leaves treated with $\mathrm{pH}$ 3.0.

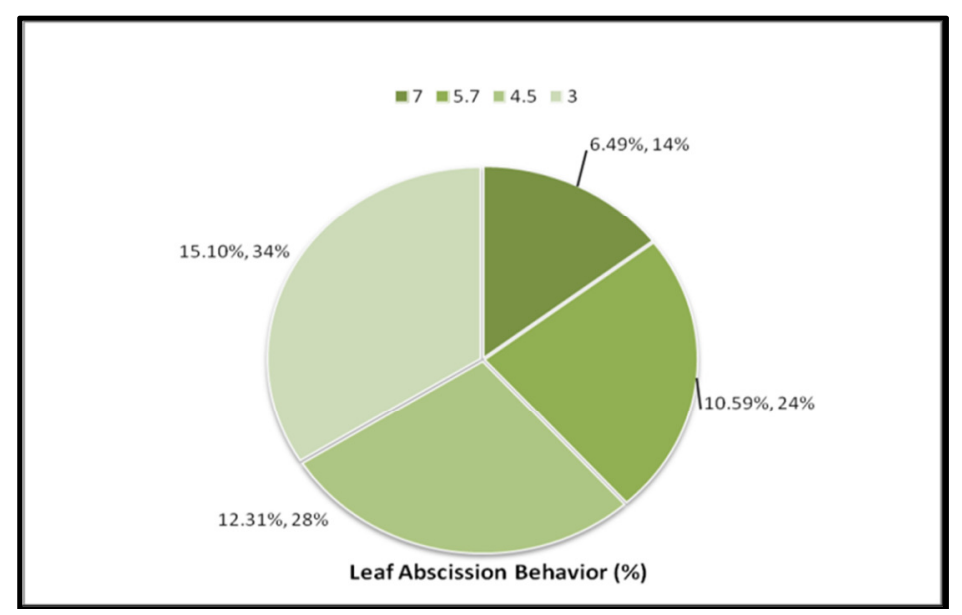

Fig. 5: Effect of SAR on \% leaf abscission at peak growth stage in Sunflower (H. annuus)

The mean of sunflower pollen germination and in vitro pollen tube measurements were significantly influenced by simulated acid rain (Figure 6). In case of control, pollen germination was recorded $86.33 \%$ and with increasing acidity a reduction in germination was observed at $\mathrm{pH} 5.7(70.88 \%), 4.5$ $(50.55 \%)$ and $3.0(43.22 \%)$. The above observations on in vitro pollen germination are similar to other studies in different crop species. Munzuroglu et al. (2003) treated the pollen of apple (Malus sylvestris) with SAR and recorded that pollen germination decreased significantly as the quantity of acid rain increased. Yao et al. (1996) also observed that direct exposure to SAR of $\mathrm{pH} 4.0$ and 3.0 reduced pollen grain germination in vivo in rice.
In vitro pollen tube length was recorded $2.73 \mu \mathrm{m}$ in case of control and pollen tube showed reduction to $2.35 \mu \mathrm{m}$ at $\mathrm{pH}$ 5.7. Pollen tube was further reduced at $\mathrm{pH} 4.5(2.22 \mu \mathrm{m})$ and at $\mathrm{pH} 3.0(1.36 \mu \mathrm{m})$ (Figure 7). It is clear from above observation that pollen tube length decreased significantly with increase in level of rain acidity. This reduction in pollen tube length is similar to Monzuroglu et al. (2003) in apple who observed that pollen tube elongation decreased as $\mathrm{pH}$ value increased and resulted in complete destruction of pollen tube. Ismail and Zohair (2013) investigated the effect of different $\mathrm{pH}$ levels on in vitro pollen germination and pollen tube growth in date palm and identified $\mathrm{pH} 6.0$ to 6.5 suitable for pollen germination with reduction in pollen germination at $\mathrm{pH} 4.0$ and below. The mean of pollen tube length 
ranged from 42.7 to $275.8 \mu \mathrm{m}$ at $\mathrm{pH}$ values 4.0 and 8.0 , respectively. These workers observed that pollen germination and pollen tube elongation were more sensitive in comparison to seed set. The SAR at $\mathrm{pH}$ 3.0 seems to be sufficiently acidic to cause direct damage to and consequent leakage of solutes from pollen tube. The present results on in vitro pollen tube length in sunflower are supported by Munzuroglu et al. (2003) and Ismail and Zohair (2013).

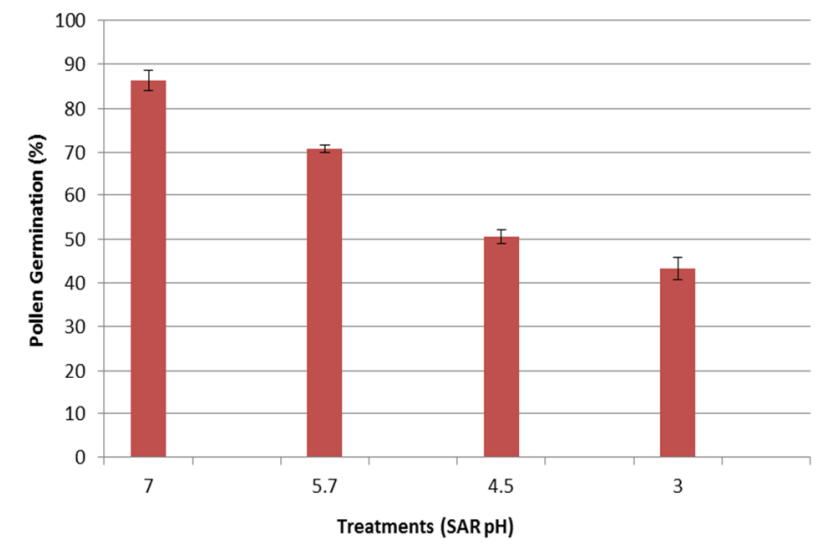

Fig. 6. Effect of SAR on in vitro pollen germination in sunflower (H. annuus)

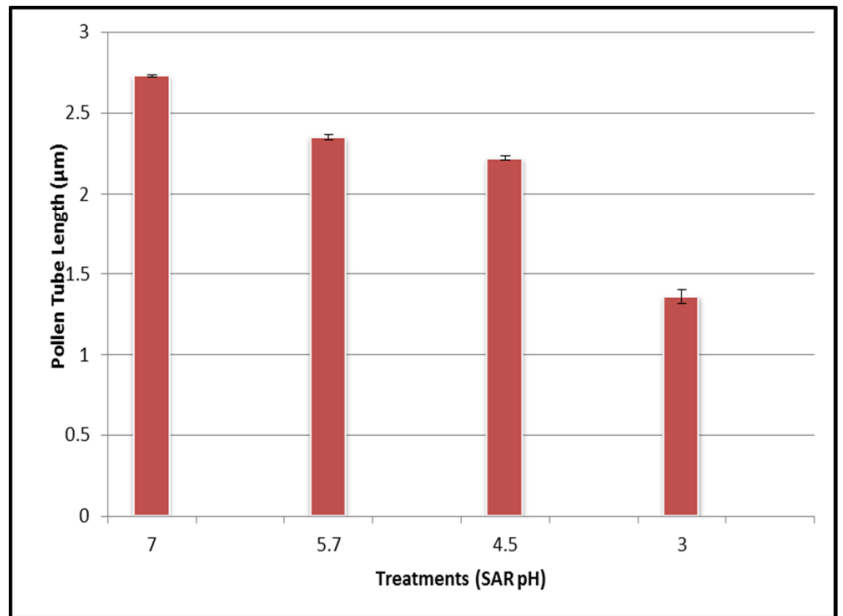

Fig. 7: Effect of SAR on in vitro pollen tube length in Sunflower (H. annuus)

Conclusion: This study proves that simulated acid rain has negative/inhibitory effects on the budding, flowering and pollen germination, and promoted leaf abscission in $H$. annuus which have direct bearing on seed and oil yield and draws attention for exploring preventive and control measures to reduce the effects of acid rain on flowering, pollen germination and productivity and breeding for acid rain tolerant varieties in crop plants.

\section{REFERENCES}

Bamidele, JF; Eguagie, MO (2015). Ecophysiological response of Capsicum annuum L. exposed to simulated acid rain. Niger. J. Biotechnol. 30: 4852 .

Chehregani, A; Kavianpour, F (2007). Effects of acid rain on the developmental stages of ovules and seed proteins in bean plants. Amer. J. Plant Physiol. 2: 367-372.

Dursun A; Kumlay, AM; Yildirim, E; Guvvenc, I (2002). Effect of simulated acid rain on plant growth and yield of tomato. Acta Hortic. 579: 245-248.

Eguagie, MO (2015). Effects of simulated acid rain 
on the growth, yield and mineral nutrient relations of Solanum lycopersicum L. Eur. J. Biotechnol. Biosci. 3: 15-18.

Ismail OM; Zohair, MM (2013). Date Palm pollen germination and growth susceptibility to different pH medium. J. Agric. Food Technol. 3: 26-30.

Kausar, S; Hussain, MA; Khan, AA (2010). Response of simulated acid rain on morphological, biochemical and leaf characteristics of wheat. Trends Biosci. 3: 34-36.

Kazim, I (2007). Response of coriander to sulphur dioxide and acid rain. MSc Dissertation, Aligarh Muslim University, Aligarh. p. 18.

Khalid, N; Qureshi, MS (2004). Changes in growth, pigmentation and yield of sunflower in response to environmental pollution of acid rain. Indus J. Biol. Sci. 1: 192-195.

Lal, N; Singh, H (2012). The effects of simulated acid rain of different $\mathrm{pH}$-levels on biomass and leaf area in Sunflower (Helianthus annuus). Curr. Bot. 3(5): 45-50.

Lal, N (2016). Effects of acid rain on plant growth and development. e-J. Sci. Technol. 11(5): 85101.

Milton, MB; Abigael, TO (2015). Effects of simulated acid rain on the morphology, phenology and yield of Okra (Abelmoschus esculentus (L). Moench). J. Environ. Sci. Comp. Sci. Engg. Technol. 4: 501-518.

Munzurolglu, O; Obek, E; Geckil, H (2003). Effects of simulated acid rain on the pollen germination and pollen tube growth of apple. Acta Biol. Hung. 54: 95-103.

Naqvi, SSM; Alam, S; Ansari, R. (2010). Chapter 3. Impact of Soil $\mathrm{pH}$ on Nutrient Uptake by Crop Plants. In: Pessarkli, M (ed.) Handbook of Plant and Crop Stress (Third edition, Revised and expanded), CRC Press, Taylor and Francis Publishing Company, Boca Raton, Florida, USA, pp. 51-60.

Pal, S; Kumar, N (2000). Effects of simulated acidic rain on yield and carbohydrate contents of green pepper (Capsicum annuum L.). Adv. Plant Sci. 13: 85-88.

Sharma, BK; Kaur, H (1994). Environmental Chemistry (IV ${ }^{\text {th }}$ Edition). Goel Publishing House, Meerut, India.

Verma, A; Tewari, A; Azami, A (2010). An impact of simulated acid rain of different $\mathrm{pH}$ levels on some major vegetable plants in India. Report and Opinion 2: 38-40.

Yao, MH; Chen, S; Tsai, JC, Liang, LS (1996). Effect of simulated acid rain on pollination of rice plants. J Agric Res China 45: 105-112. 